\title{
Comparing the initiation of adjuvant chemotherapy after robotic and laparoscopic colon cancer surgeries: A case-controlled study with propensity score matching
}

\author{
Sanghoon Kim, Sung Uk Bae, Seong Kyu Baek, Woon Kyung Jeong \\ Department of Surgery, Keimyung University Dongsan Medical Center, Keimyung University School of Medicine, Daegu, Korea
}

Purpose: Early initiation of adjuvant chemotherapy after colon cancer surgery has shown better oncologic outcomes in previous studies. However, the clinical impact of robotic and laparoscopic surgeries on the initiation of adjuvant chemotherapy has not been widely evaluated. Hence, the study's aim was to compare the influence of both surgical approaches on the initiation of adjuvant chemotherapy after colon cancer surgery.

Methods: From June 2011 to September 2017, 289 patients underwent curative robotic or laparoscopic surgery followed by adjuvant chemotherapy for stage II and III colon cancer. To control for different demographic factors in the two groups, propensity score case matching was used at a 1:4 ratio. Finally, 190 patients were matched with 38 patients of the robotic surgery group and 152 patients of the laparoscopic surgery group.

Results: The operation time was longer in the robotic surgery group (297 minutes vs. 170 minutes, respectively; $\mathrm{P}<0.001$ ). However, conversion rate, number of retrieved lymph nodes, first flatus, first soft diet, length of stay, postoperative complication rate, and Clavien-Dindo grade were not significantly different between the two groups. Additionally, there was no difference in the time to initiation of adjuvant chemotherapy between the two groups ( 31.5 days vs. 29.0 days, respectively; $P=0.226$ ). Disease-free and overall survival rates were also not significantly different.

Conclusion: Robotic and laparoscopic surgeries showed no different impact on the initiation of adjuvant chemotherapy. This finding suggests that the two surgical approaches offer similar postoperative outcomes.

Keywords: Colonic neoplasm, Adjuvant chemotherapy, Minimally invasive surgery, Robotic surgical procedure, Laparoscopy

\section{INTRODUCTION}

Adjuvant chemotherapy after resection of the primary colon cancer reduces the risk of disease recurrence by $40 \%$ and mortality by

Received: Apr 13, 2020 Revised: Jun 22, 2020 Accepted: Jun 26, 2020

Correspondence to: Woon Kyung Jeong

Department of Surgery, Keimyung University Dongsan Medical Center,

1035 Dalgubeol-daero, Dalseo-gu, Daegu 42601, Korea

Tel: +82-53-258-7879, Fax: +82-53-258-4710

E-mail: shinycloud@dsmc.or.kr

ORCID: Sanghoon Kim (https://orcid.org/0000-0001-9481-3042), Sung Uk Bae (https://orcid.org/0000-0002-7876-4196), Seong Kyu Baek (https://orcid.org/00000001-6427-8675), Woon Kyung Jeong (https://orcid.org/0000-0001-8421-218X)

Copyright (C) 2020 Korean Society of Surgical Oncology

This is an Open Access article distributed under the terms of the Creative Commons Attribution Non-Commercial License (http://creativecommons.org/licenses/by-nc/4.0) which permits unrestricted non-commercial use, distribution, and reproduction in any medium, provided the original work is properly cited.
$33 \%$ [1]. Early initiation of adjuvant chemotherapy after colon cancer surgery has shown better oncologic outcomes in previous studies [2-6]. The European Society for Medical Oncology (ESMO) guideline recommends that adjuvant chemotherapy should be given as soon as possible, from the third to the 12th week pos-toperatively [7]. In contrast, the National Comprehensive Cancer Network guideline does not recommend a precise timing of adjuvant chemotherapy, but it introduces some studies that revealed how starting early adjuvant chemotherapy showed better oncologic outcomes [8]. One of the benefits of minimally invasive surgery such as laparoscopic and robotic surgeries is earlier postoperative recovery than open surgery $[9,10]$. However, the clinical impact of laparoscopic and robotic surgeries on the initiation of adjuvant chemotherapy has not been widely evaluated. Therefore, this study's aim was to compare those surgical approaches' influence on the initiation of adjuvant chemotherapy after colon cancer surgery. 


\section{METHODS}

\section{Study population and study design}

From June 2011 to September 2017, 830 consecutive patients underwent colon cancer surgery at Keimyung University Dongsan Medical Center. Patient data were collected from the prospectively managed electric database. Thirty patients who were less than 20 years old, underwent emergency surgery, or had simultaneous surgery for other organ diseases were excluded. Four hundred and ninety-one out of 800 patients had pathologic stage II and III colon cancer (245 and 246, respectively). Of the 491 patients, 327 received adjuvant chemotherapy (120 and 207, respectively). To compare minimally invasive surgery, 38 patients who underwent open laparotomy were excluded.

Ultimately, 289 patients were enrolled. Thirty-eight patients underwent robotic surgery (RS) and 251 patients underwent laparoscopic surgery (LS). To control for different demographic factors in the two groups, propensity score case matching was used at a 1:4 ratio. Propensity scores were generated with the baseline characteristics, including age, sex, body mass index, American Society of Anesthesiologists (ASA) score, previous abdominal surgery, tumor location and pathologic stage. Finally, 190 patients were matched with 38 patients of RS group and 152 patients of LS group (Fig. 1).

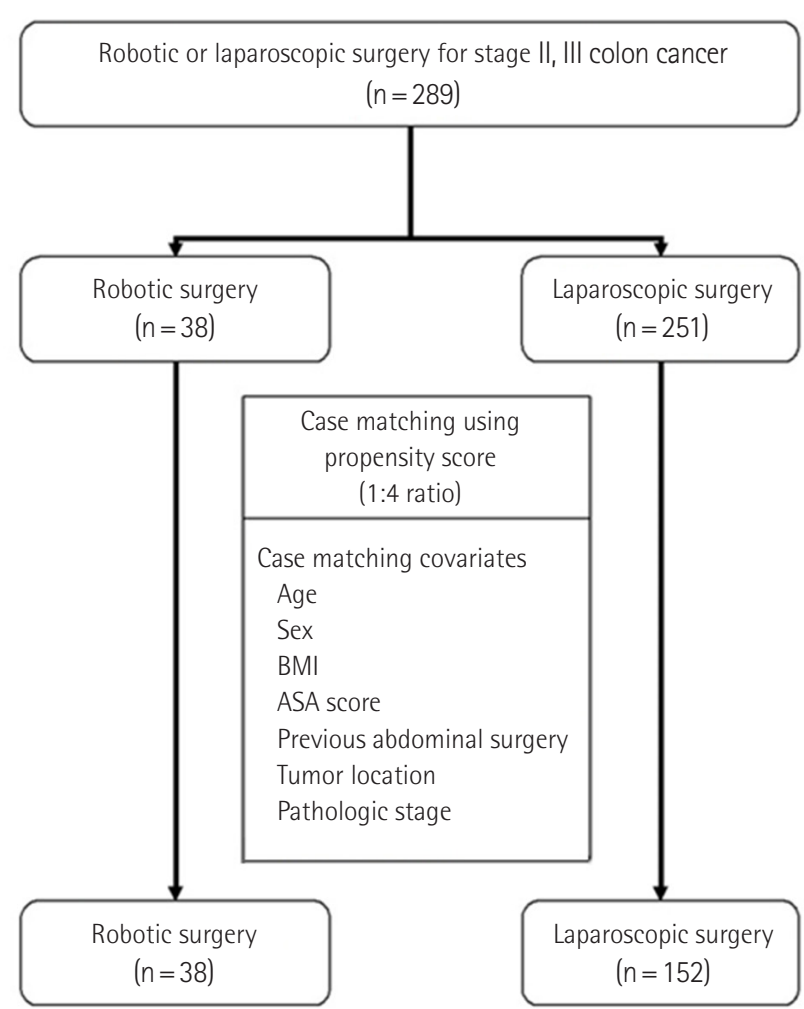

Fig. 1. Study design. BMI, body mass index; ASA, American Society of Anesthesiologists.

Table 1. Preoperative and pathologic factors (before and after case matching)

\begin{tabular}{|c|c|c|c|c|c|c|}
\hline \multirow[b]{2}{*}{ Variable } & \multicolumn{3}{|c|}{ Before matching } & \multicolumn{3}{|c|}{ After matching } \\
\hline & $\begin{array}{l}\text { Robotic } \\
(n=38)\end{array}$ & $\begin{array}{l}\text { Laparoscopic } \\
\quad(n=251)\end{array}$ & P-value & $\begin{array}{l}\text { Robotic } \\
(n=38)\end{array}$ & $\begin{array}{l}\text { Laparoscopic } \\
(n=152)\end{array}$ & P-value \\
\hline Age $(y r)$ & $60.9 \pm 9.1$ & $66.3 \pm 10.5$ & 0.003 & $60.9 \pm 9.0$ & $62.3 \pm 10.0$ & 0.428 \\
\hline Sex & & & 0.367 & & & 0.536 \\
\hline Male & $24(63.2)$ & $139(55.4)$ & & $24(63.2)$ & $104(68.4)$ & \\
\hline Female & $14(36.8)$ & $112(44.6)$ & & $14(36.8)$ & $48(31.6)$ & \\
\hline $\mathrm{BMI}\left(\mathrm{kg} / \mathrm{m}^{2}\right)$ & $33.4 \pm 62.6$ & $23.7 \pm 3.2$ & 0.346 & $33.4 \pm 62.6$ & $23.9 \pm 3.0$ & 0.354 \\
\hline ASA score & & & 0.001 & & & $0.220^{\mathrm{a})}$ \\
\hline l & $20(52.6)$ & $64(25.5)$ & & $20(52.6)$ & $57(37.5)$ & \\
\hline$\|$ & $17(44.7)$ & $145(57.8)$ & & $17(44.7)$ & $87(57.2)$ & \\
\hline III & $1(2.6)$ & $42(16.7)$ & & $1(2.6)$ & $8(5.3)$ & \\
\hline Previous abdominal surgery & $10(26.3)$ & 46 (18.3) & 0.246 & $10(26.3)$ & $34(22.4)$ & 0.606 \\
\hline Tumor location & & & 0.013 & & & $0.543^{\mathrm{a})}$ \\
\hline Proximal colon & $6(15.8)$ & $100(39.8)$ & & $6(15.8)$ & $33(21.7)$ & \\
\hline Distal colon & 32 (84.2) & $149(59.4)$ & & 32 (84.2) & 117 (77.0) & \\
\hline Multiple & 0 & $2(0.8)$ & & 0 & $2(1.3)$ & \\
\hline AJCC stage & & & 0.843 & & & 0.763 \\
\hline$\|$ & $13(34.2)$ & $90(35.9)$ & & 13 (34.2) & $56(36.8)$ & \\
\hline III & $25(65.8)$ & $161(64.1)$ & & $25(65.8)$ & $96(63.2)$ & \\
\hline
\end{tabular}

Values are presented as mean \pm standard deviation or number (\%).

BMI, body mass index; ASA, American Society of Anesthesiologists; AJCC, American Joint Committee on Cancer.

a) Fisher exact test. 


\section{Statistical analysis}

Statistical analyses were performed with PASW Statistics 18 software (SPSS Inc., Chicago, IL, USA) and R 3.2.2 (R Foundation for Statistical Computing, Vienna, Austria). The data are displayed as frequencies and percentages for categorical variables and were analyzed with the Pearson's chi-square test or Fisher exact test. The Kolmogorov-Smirnov test was used to test the distribution of continuous variables. Normally distributed variables were examined with Student t-test and the results are presented as mean (standard deviation). Conversely, non-normally distributed continuous variables were subjected to examination with the Mann-Whitney U test, and the results are expressed as median (interquartile range). The Kaplan-Meier method was used to analyze survival. Additionally, prognostic factors were analyzed using the Cox-regression model. Two-tailed values of $\mathrm{P}<0.05$ were considered statistically significant.

\section{Ethics statement}

This study protocol was reviewed and approved by the Institutional Review Board of the Keimyung University Dongsan Medical Center (IRB No. 2019-12-022). Informed consent was waived due to the retrospective design of the study.

\section{RESULTS}

Demographic and preoperative data before and after propensity score matching

Before propensity score case matching, a higher mean age, higher percentage of ASA scores, and less percentage of distal colon cancers were noted in the LS group.

The mean age was 60.9 years in the RS group and 66.3 years in the LS group ( $\mathrm{P}=0.003)$. ASA scores I, II, and III were 52.6\%, 44.7\%, and $2.6 \%$ in the RS group and $25.5 \%, 57.8 \%$, and $16.7 \%$ in the LS group, respectively $(\mathrm{P}=0.001)$. Tumors located in the proximal colon, distal colon, and multiple sites were $15.8 \%, 84.2 \%$, and $0 \%$ in the RS group and $39.8 \%, 59.4$, and $0.8 \%$ in the LS group $(\mathrm{P}=0.013)$.

After propensity score case matching, these factors were well balanced. The mean ages were 60.9 years and 62.3 years, respectively $(\mathrm{P}=0.428)$. The ASA score became similar $(52.6 \%, 44.7 \%$, and $2.6 \%$ vs. $37.5 \%, 57.2 \%$, and $5.3 \%$, respectively; $\mathrm{P}=0.220)$. Moreover, tumor location was not significantly different $(15.8 \%, 84.2 \%$, and $0 \%$ vs. $21.7 \%, 77.0$, and $1.3 \%$, respectively; $\mathrm{P}=0.543$ ) (Table 1 ).

\section{Pathologic results and chemotherapy regimen after propensity score matching}

Percentages of AJCC stages II and III in both groups were simi$\operatorname{lar}(34.2 \%$ and $65.8 \%$ vs. $36.8 \%$ and $63.2 \%$, respectively; $\mathrm{P}=0.763$ )
(Table 1). Other pathologic data including T stage, $\mathrm{N}$ stage, differentiation, lymphovascular invasion, and perineural invasion were not significantly different between the two groups. FOLFOX (5-fluorouracil, leucovorin, and oxaliplatin) was the most used adjuvant chemotherapy regimen (78.9\% vs. $88.2 \%$, respectively; $\mathrm{P}=0.186)$. The mean number of retrieved lymph nodes was not different between the two groups (Table 2).

\section{Perioperative results after propensity score matching}

The median operation time was longer in the RS group than in the LS group (297 minutes vs. 170 minutes; respectively; $\mathrm{P}<0.001$ ) (Table 3). Despite that conversion was required only in the LS group, statistical difference was not shown between both groups $(0$ case vs. 6 cases, respectively; $\mathrm{P}=0.257$ ). The reasons for conversion were dense adhesions of the small intestine caused by previous surgery $(n=3)$, invasion of the abdominal wall $(n=2)$, and a huge

Table 2. Pathologic results and chemotherapy regimen (after case matching)

\begin{tabular}{|c|c|c|c|}
\hline Variable & $\begin{array}{l}\text { Robotic } \\
(n=38)\end{array}$ & $\begin{array}{l}\text { Laparoscopic } \\
\qquad(n=152)\end{array}$ & P-value \\
\hline pT stage & & & $0.232^{\mathrm{a})}$ \\
\hline 1 & $4(10.5)$ & $6(3.9)$ & \\
\hline 2 & $3(7.9)$ & $6(3.9)$ & \\
\hline 3 & $25(65.8)$ & 105 (69.1) & \\
\hline 4 & $6(15.8)$ & $35(23.0)$ & \\
\hline pN stage & & & 0.693 \\
\hline 0 & $13(34.2)$ & $56(36.8)$ & \\
\hline 1 & $18(47.4)$ & $61(40.1)$ & \\
\hline 2 & $7(18.4)$ & $35(23.0)$ & \\
\hline Retrieved lymph node & $26 \pm 14$ & $25 \pm 9$ & 0.364 \\
\hline Differentiation & & & 0.395 \\
\hline Well & $1(2.6)$ & $1(0.7)$ & \\
\hline Moderately & 34 (89.5) & 131 (86.2) & \\
\hline Poorly & $3(7.9)$ & $20(13.2)$ & \\
\hline Lymphovascular invasion & & & 0.259 \\
\hline Negative & $17(44.7)$ & $53(34.9)$ & \\
\hline Positive & $21(55.3)$ & $99(65.1)$ & \\
\hline Perineural invasion & & & 0.325 \\
\hline Negative & $27(71.1)$ & $95(62.5)$ & \\
\hline Positive & $11(28.9)$ & $57(37.5)$ & \\
\hline Chemotherapy regimen & & & 0.186 \\
\hline FOLFOX & 30 (78.9) & $134(88.2)$ & \\
\hline 5-FU/LV & $2(5.3)$ & $8(5.3)$ & \\
\hline Capecitabine & $6(15.8)$ & $10(6.6)$ & \\
\hline
\end{tabular}

Values are presented as number (\%) or mean \pm standard deviation. pT, pathologic tumor; pN, pathologic node; FOLFOX, 5-fluorouracil, leucovorin, and oxaliplatin; 5-FU/LV, 5-fluorouracil/leucovorin.

a) Fisher exact test. 
Table 3. Perioperative results (after case matching)

\begin{tabular}{|c|c|c|c|}
\hline Variable & $\begin{array}{l}\text { Robotic } \\
(n=38)\end{array}$ & $\begin{array}{l}\text { Laparoscopic } \\
\qquad(n=152)\end{array}$ & P-value \\
\hline Conversion & 0 & $6(3.9)$ & $0.257^{a)}$ \\
\hline Operation time (min) & 297 (219-374) & $170(142-230)$ & $<0.001$ \\
\hline Postoperative complication & $11(28.9)$ & 30 (19.7) & 0.217 \\
\hline SSI, superficial & 2 & 9 & \\
\hline SSI, organ/space & 0 & 3 & \\
\hline Anastomosis leakage & 2 & 2 & \\
\hline PMC & 2 & 5 & \\
\hline Thrombophlebitis & 0 & 1 & \\
\hline FUO & 0 & 1 & \\
\hline Ischemic colitis & 0 & 2 & \\
\hline Paralytic ileus & 2 & 3 & \\
\hline Small bowel obstruction & 2 & 2 & \\
\hline Urinary retention & 0 & 1 & \\
\hline Chyle leakage & 1 & 1 & \\
\hline Clavien-Dindo grade & & & $0.835^{\text {a) }}$ \\
\hline I & $3(27.3)$ & $9(30.0)$ & \\
\hline$\|$ & $8(72.7)$ & 19 (63.3) & \\
\hline Illa & 0 & $1(3.3)$ & \\
\hline$\| l l b$ & 0 & $1(3.3)$ & \\
\hline First flatus (day) & $3.0(2.0-4.0)$ & $3.0(2.0-4.0)$ & 0.961 \\
\hline First soft diet (day) & $7.0(6.8-8.0)$ & $7.0(6.0-8.0)$ & 0.062 \\
\hline Length of stay (day) & $10.0(9.0-13.0)$ & $10(9.0-12.0)$ & 0.564 \\
\hline Time to initiation of adjuvant chemotherapy (day) & $31.5(27.0-34.3)$ & $29.0(25.0-35.0)$ & 0.226 \\
\hline
\end{tabular}

Values are presented as number (\%) or median (interquartile range).

SSI, surgical site infection; PMC, pseudomembranous colitis; FUO, fever of unknown origin.

a) Fisher exact test.

cancer mass $(\mathrm{n}=1)$.

Postoperative complication rate seemed higher in the RS group; however, there was no statistical difference $(11 / 38,28.9 \%$ vs. 30/152, 19.7\%, respectively; $\mathrm{P}=0.217$ ). Clavien-Dindo grade also was not significantly different between the two groups. Most complications were classified as Clavien-Dindo grade I or II in both groups. Grade III complications occurred in two patients in the LS group. One patient had organ/space surgical site infection, which was treated with percutaneous drainage (grade IIIa). Another patient experienced anastomotic leakage requiring laparotomy and diverting ileostomy (grade IIIb). None of the patients in the RS group had grade III complications.

There were no differences in the length of stay, first flatus, and first soft diet. Regarding the time to initiation of adjuvant chemotherapy, there was no difference between the two groups as well ( 31.5 vs. 29.0 days, respectively; $\mathrm{P}=0.226$ ).

\section{Disease-free and overall survival rates}

Survival analysis between RS and LS groups is shown in Fig. 2. The 5-year overall survival and disease-free survival rates were not significantly different between the two groups. The 5 -year overall survival rate was $86.1 \%$ in the RS group and $78.0 \%$ in the LS group $(\mathrm{P}=0.356)$. Meanwhile, the 5 -year disease-free survival rate was the same in both groups ( $82.9 \%$ vs. $82.9 \%$, respectively; $\mathrm{P}=0.987$ ).

In stage II colon cancer patients, the 5-year overall survival rate was lower in the RS group (66.7\%) than in the LS group (82.5\%), but statistical difference was not shown $(\mathrm{P}=0.810)$. The 5 -year disease-free survival rate was similar between the two groups ( $91.7 \mathrm{vs.}$ $90.9 \%$, respectively; $\mathrm{P}=0.997$ ) (Fig. 3). In stage III colon cancer patients, the 5-year overall survival rate was higher in the RS group (95.0\%) than in the LS group (74.8\%) without statistical difference $(\mathrm{P}=0.173)$. Moreover, the 5 -year disease-free survival rate was similar (77.3 vs. 77.8\%, respectively; $\mathrm{P}=0.967$ ) (Fig. 4).

\section{Risk factors of disease-free survival and overall survival}

Univariate and multivariate analyses were carried out to assess the surgical approach (robotic and laparoscopic surgeries) as an independent prognostic factor with respect to overall survival and dis- 

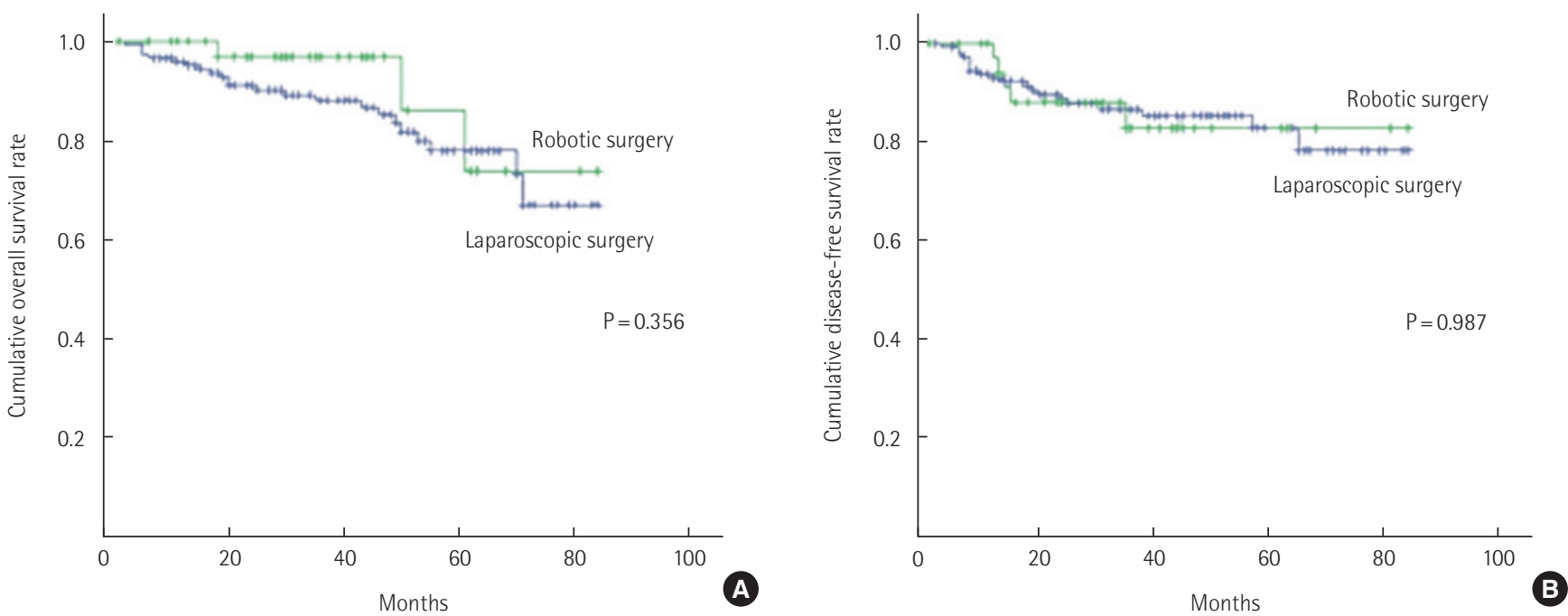

Fig. 2. Five-year overall survival curves (A) and disease-free survival curves (B) between robotic and laparoscopic surgery groups.
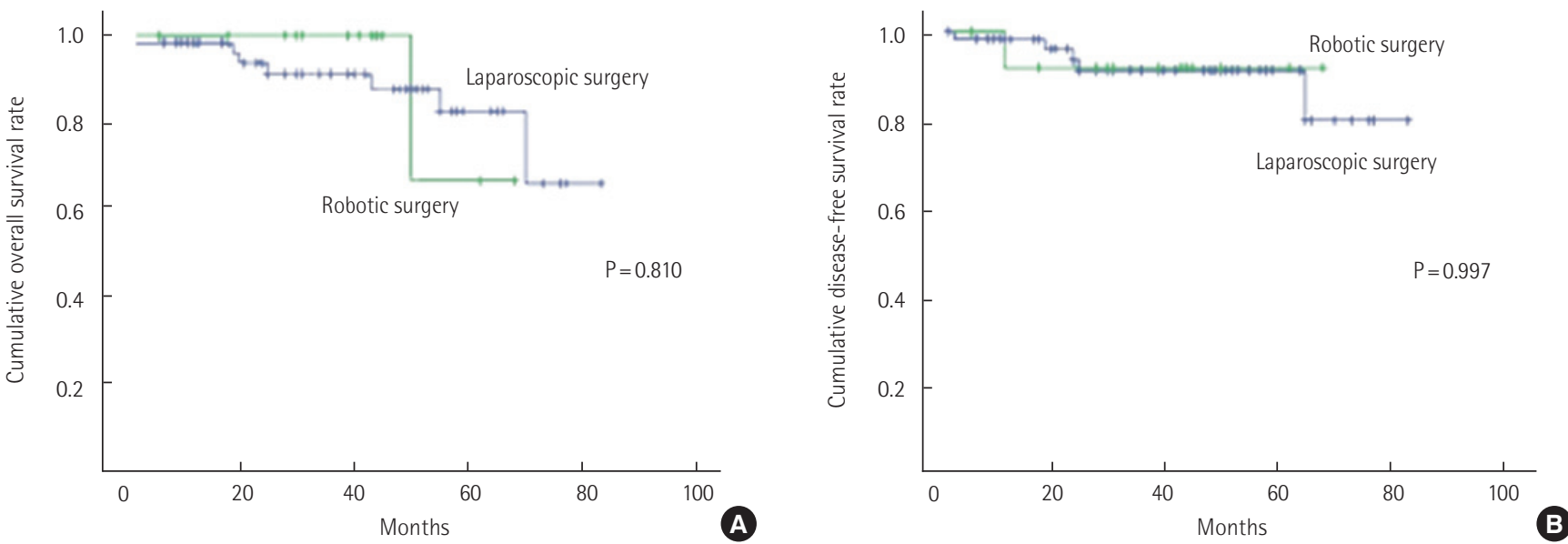

Fig. 3. Five-year overall survival curves (A) and disease-free survival curves (B) in patients with stage II.
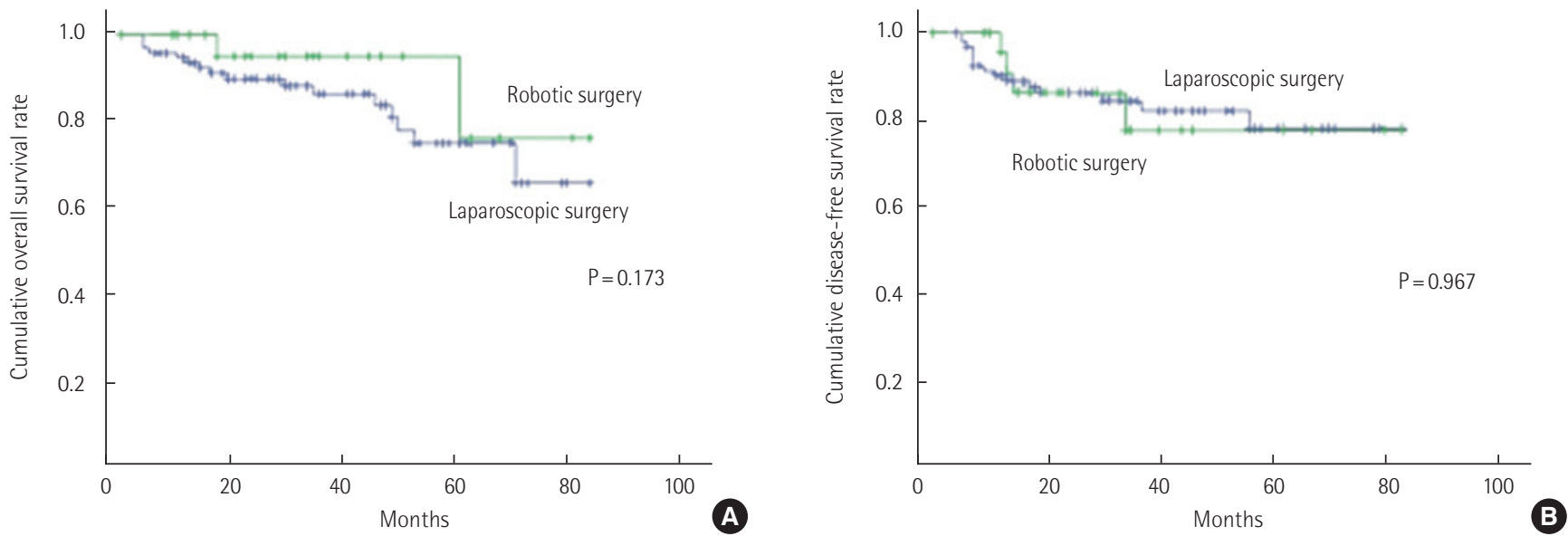

Fig. 4. Five-year overall survival curves (A) and disease-free survival curves (B) in patients with stage III. 
Table 4. Univariate and multivariate analyses of risk factors for overall survival after surgery

\begin{tabular}{|c|c|c|c|c|}
\hline \multirow{2}{*}{ Variable } & \multicolumn{2}{|c|}{ Univariate } & \multicolumn{2}{|c|}{ Multivariate } \\
\hline & $\mathrm{HR}(95 \% \mathrm{Cl})$ & P-value & $\mathrm{HR}(95 \% \mathrm{Cl})$ & P-value \\
\hline Age (yr) & $1.285(0.583-2.835)$ & 0.534 & & \\
\hline \multicolumn{5}{|l|}{$<60$ vs. $\geq 60$} \\
\hline Sex & 0.345 (0.119-1.000) & 0.050 & & \\
\hline \multicolumn{5}{|l|}{ Male vs. female } \\
\hline BMI $\left(\mathrm{kg} / \mathrm{m}^{2}\right)$ & 1.054 (0.478-2.324) & 0.896 & & \\
\hline \multicolumn{5}{|l|}{$<25$ vs. $\geq 25$} \\
\hline ASA score & $2.010(0.845-4.781)$ & 0.115 & & \\
\hline \multicolumn{5}{|l|}{ | vs. ||, ||| } \\
\hline Surgical approach & 0.571 (0.171-1.908) & 0.363 & & \\
\hline \multicolumn{5}{|l|}{ Laparoscopic vs. robotic } \\
\hline Tumor location & 1.080 (0.407-2.868) & 0.877 & & \\
\hline \multicolumn{5}{|l|}{ Proximal vs. distal colon } \\
\hline pT stage & 1.379 (0.324-5.869) & 0.663 & & \\
\hline \multicolumn{5}{|l|}{ T1, 2 vs. T3, 4} \\
\hline pN stage & 1.371 (0.595-3.158) & 0.459 & & \\
\hline \multicolumn{5}{|l|}{ No vs. N1, 2} \\
\hline AJCC stage & 1.371 (0.595-3.158) & 0.459 & & \\
\hline \multicolumn{5}{|l|}{ || vs. III } \\
\hline Differentiation & 3.385 (1.409-8.132) & 0.006 & 2.808 (1.160-6.798) & 0.022 \\
\hline \multicolumn{5}{|l|}{ WD+MD vs. PD } \\
\hline Lymphovascular invasion & 3.190 (0.952-10.684) & 0.060 & & \\
\hline \multicolumn{5}{|l|}{ Absent vs. present } \\
\hline Perineural invasion & $2.227(1.023-4.851)$ & 0.044 & 2.681 (1.182-6.085) & 0.018 \\
\hline \multicolumn{5}{|l|}{ Absent vs. present } \\
\hline Chemotherapy regimen & 3.699 (1.471-9.304) & 0.005 & 4.087 (1.538-10.860) & 0.005 \\
\hline \multicolumn{5}{|l|}{ FOLFOX vs. 5-FU/LV, capecitabine } \\
\hline Complication & $0.880(0.331-2.337)$ & 0.798 & & \\
\hline \multicolumn{5}{|l|}{ Absent vs. present } \\
\hline Length of stay (day) & $0.591(0.256-1.363)$ & 0.217 & & \\
\hline$\leq 10$ vs. $>10$ & & & & \\
\hline Time to initiation of adjuvant chemotherapy (day) & $0.559(0.243-1.286)$ & 0.171 & & \\
\hline$\leq 30$ vs. $>30$ & & & & \\
\hline
\end{tabular}

HR, hazard ratio; $\mathrm{Cl}$, confidence interval; BMI, body mass index; ASA, American Society of Anesthesiologists; pT, pathologic tumor; pN, pathologic node; AJCC, American Joint Committee on Cancer; WD, well differentiation; MD, moderate differentiation; PD, poor differentiation; FOLFOX, 5-fluorouracil, leucovorin, and oxaliplatin; 5-FU/LV, 5-fluorouracil/leucovorin.

ease-free survival.

Factors associated with poorer overall survival in univariate analysis included poor differentiation, perineural invasion, and 5-fluorouracil/leucovorin (5-FU/LV) or capecitabine chemotherapy regimen. Similarly, in multivariate analysis, the abovementioned factors were also associated with poorer overall survival (Table 4).

During a median follow-up period of 35 months, 25 patients experienced colon cancer recurrence $(5 / 38,13.2 \%$ vs. $20 / 152,13.2 \%$, respectively). In univariate analysis, the factors associated with poorer disease-free survival were poor differentiation, lymphovas- cular invasion, and perineural invasion. Meanwhile, in multivariate analysis, only poor differentiation and lymphovascular invasion were associated with poorer disease-free survival (Table 5).

\section{DISCUSSION}

Minimally invasive LS for colon cancer has been accepted widely for short-term outcomes, such as reduced postoperative pain, rapid resumption of bowel transit, better cosmesis, and a reduced postoperative systemic immune response compared to open sur- 
Table 5. Univariate and multivariate analyses of risk factors for disease-free survival after surgery

\begin{tabular}{|c|c|c|c|c|}
\hline \multirow{2}{*}{ Variable } & \multicolumn{2}{|c|}{ Univariate } & \multicolumn{2}{|c|}{ Multivariate } \\
\hline & HR (95\% Cl) & P-value & $\operatorname{HR}(95 \% \mathrm{Cl})$ & P-value \\
\hline $\begin{array}{l}\text { Age (yr) } \\
<60 \text { vs. } \geq 60\end{array}$ & $1.265(0.568-2.817)$ & 0.565 & & \\
\hline $\begin{array}{l}\text { Sex } \\
\text { Male vs. female }\end{array}$ & $0.593(0.236-1.485)$ & 0.264 & & \\
\hline $\begin{array}{l}\text { BMI }(\mathrm{kg} / \mathrm{m} 2) \\
\quad<25 \text { vs. } \geq 25\end{array}$ & $1.124(0.505-2.502)$ & 0.775 & & \\
\hline $\begin{array}{l}\text { ASA score } \\
\text { | vs. ||, ||| }\end{array}$ & $1.135(0.510-2.528)$ & 0.756 & & \\
\hline $\begin{array}{l}\text { Surgical approach } \\
\text { Laparoscopic vs. robotic }\end{array}$ & 1.008 (0.378-2.688) & 0.987 & & \\
\hline $\begin{array}{l}\text { Tumor location } \\
\text { Proximal vs. distal colon }\end{array}$ & $1.143(0.491-4.172)$ & 0.512 & & \\
\hline $\begin{array}{l}\text { pT stage } \\
\text { T1, } 2 \text { vs. T3, } 4\end{array}$ & $2.996(0.405-22.171)$ & 0.283 & & \\
\hline $\begin{array}{l}\text { pN stage } \\
\text { N0 vs. N1, } 2\end{array}$ & $2.013(0.803-5.043)$ & 0.136 & & \\
\hline $\begin{array}{l}\text { AJCC stage } \\
\text { \| vs. III }\end{array}$ & $2.013(0.803-5.043)$ & 0.136 & & \\
\hline $\begin{array}{l}\text { Differentiation } \\
\text { WD+MD vs. PD }\end{array}$ & 3.403 (1.413-8.193) & 0.006 & $3.182(1.318-7.685)$ & 0.010 \\
\hline $\begin{array}{l}\text { Lymphovascular invasion } \\
\text { Absent vs. present }\end{array}$ & $5.948(1.401-25.260)$ & 0.016 & $4.788(1.116-20.536)$ & 0.035 \\
\hline $\begin{array}{l}\text { Perineural invasion } \\
\text { Absent vs. present }\end{array}$ & $2.578(1.165-5.705)$ & 0.019 & $2.109(0.945-4.705)$ & 0.068 \\
\hline $\begin{array}{l}\text { Chemotherapy regimen } \\
\text { FOLFOX vs. 5-FU/LV, capecitabine }\end{array}$ & $2.280(0.681-7.635)$ & 0.181 & & \\
\hline $\begin{array}{l}\text { Complication } \\
\text { Absent vs. present }\end{array}$ & $1.438(0.601-3.445)$ & 0.415 & & \\
\hline $\begin{array}{l}\text { Length of stay (day) } \\
\quad \leq 10 \text { vs. }>10\end{array}$ & $0.824(0.364-1.869)$ & 0.644 & & \\
\hline $\begin{array}{l}\text { Time to initiation of adjuvant chemotherapy (day) } \\
\leq 30 \text { vs. }>30\end{array}$ & $1.130(0.515-2.479)$ & 0.760 & & \\
\hline
\end{tabular}

$\mathrm{HR}$, hazard ratio; $\mathrm{Cl}$, confidence interval; BMI, body mass index; ASA, American Society of Anesthesiologists; pT, pathologic tumor; pN, pathologic node; AJCC, American Joint Committee on Cancer; WD, well differentiation; MD, moderate differentiation; PD, poor differentiation; FOLFOX, 5-fluorouracil, leucovorin, and oxaliplatin; 5-FU/LV, 5-fluorouracil/leucovorin.

gery [11]. Long-term oncologic outcomes are at least equivalent in both minimally invasive laparoscopic and open surgeries [12,13].

When compared to the LS, the advanced techniques of the robotic surgical system provide better visualization and movements, enabling more precise and safer surgery. This led to the rapid adoption of the robotic surgical system by the enthusiastic surgeons. In the field of colon cancer surgery, the expectation that RS offers much better benefits than LS has not been realized. In the literature, the comparative studies comparing clinical outcomes between the two surgeries have not shown consistent results. A population analysis comparing robotic and laparoscopic colectomies for colon cancer reported that robotic and laparoscopic groups were similar in short-term outcomes. However, the robotic group was associated with decreased conversion to an open surgery and length of stay [14]. In a randomized, controlled study comparing robotic and laparoscopic surgeries for right colon cancer, conversion to an open surgery, length of stay, and morbidity were similar, but the RS group had longer operation time and higher cost [15].

We supposed that a different method other than generally used 
ones is necessary to compare robotic and laparoscopic surgeries for colon cancer. The interval between surgical resection and adjuvant chemotherapy would be a proliferation period of micrometastases $[16,17]$. Hence, early initiation of adjuvant chemotherapy could result in better oncologic outcomes. Occasionally though, patients' health factors or surgical complications prevent the early initiation. Therefore, surgical techniques that make recovery faster and have less surgical complications are required for early initiation of adjuvant chemotherapy. Based on these facts, the interval between surgical resection and adjuvant chemotherapy might indirectly represent the extent of tissue damage by surgical technique, recovery from the surgery, and oncologic outcome. Thus, we decided to use the interval between surgical resection and adjuvant chemotherapy as a parameter comparing robotic and laparoscopic surgeries for colon cancer.

In the literature, there is one study comparing open, laparoscopic and robotic surgeries in the initiation timing of adjuvant chemotherapy. It revealed that laparoscopic and robotic surgeries resulted in shorter time for initiation of chemotherapy than open surgery. When comparing laparoscopic and robotic surgeries, RS showed shorter time for initiation than LS. That was, however, a retrospective study limited by selection bias [18]. To reduce the selection bias, we used propensity score matching.

In our study, there was no difference in the time to initiation of adjuvant chemotherapy between the two groups (31.5 days vs. 29.0 days, respectively; $\mathrm{P}=0.226$ ). Other factors, associated with the initiation of adjuvant chemotherapy, also showed similar results, which include conversion rate to open surgery, return of bowel function, postoperative complication rates, and length of stay.

The robotic system allows the surgeon to perform more delicate and complex movement with stability than laparoscopy. These advantages enhance the precision and accuracy of anatomical dissection, especially in the deep and narrow pelvis [19]. The surgical field for colon cancer surgery, however, is much wider than the pelvic cavity, which does not require much the advantages of RS. The surgical procedure for colon cancer is closely identical in the two surgeries, and intraperitoneal tissue trauma is also similar. These factors may in part explain that postoperative data are not significantly different between the two groups.

Five-year overall survival and disease-free survival rates were not significantly different between robotic and LS groups in this study. In univariate and multivariate analyses, surgical approach was not an independent prognostic factor with respect to overall survival and disease-free survival. In the present study, robotic and laparoscopic surgeries for colon cancer showed equivalent influence on oncologic outcomes. A limited number of studies comparing long-term oncologic outcomes of the two surgeries have been conducted, where a discrepancy among the oncologic outcomes was found. Moreover, a retrospective study of right colectomy for colon cancer demonstrated that RS is related to higher lymph node retrieval compared to both open and laparoscopic surgeries. The influence of this result on the oncologic outcomes was not evaluated [20]. A cohort study analyzing long-term oncologic outcomes found no difference in disease-free survival, allcause mortality and recurrence-free survival between two surgeries [21]. The comparison study of robotic and laparoscopic surgeries for right colon cancer showed similar 5-year disease-free and overall survival rates [15]. In contrast, one study demonstrated higher 5-year overall survival rate in the RS group, even though lymph node retrieval was similar [14]. These differences have raised the need for more studies providing highly convincing evidence and reliability.

There are some limitations in this study. Firstly, this is not a randomized, controlled study. Primarily, selection bias could be a weakness of this study. Propensity score matching, however, was used to overcome the selection bias and improve reliability. Secondly, data in this study were collected in a single center, and the number of enrolled cases is relatively small. A multicenter trial would therefore be necessary to gather larger data. Thirdly, assessment regarding the quality of life was not included as well as pain score, cosmesis, patients' satisfaction, etc. Therefore, a prospective study assessing the quality of life is anticipated.

In conclusion, robotic and laparoscopic surgeries showed no different impact on the initiation of adjuvant chemotherapy. This finding suggests that the two surgical approaches offer similar postoperative outcomes. It is however important to reveal the other benefits of RS over LS for colon cancer, compensating the high cost of RS.

\section{CONFLICT OF INTEREST}

No potential conflict of interest relevant to this article was reported.

\section{REFERENCES}

1. Moertel CG, Fleming TR, Macdonald JS, Haller DG, Laurie JA, Goodman PJ, et al. Levamisole and fluorouracil for adjuvant therapy of resected colon carcinoma. N Engl J Med 1990;322:352-8.

2. Arkenau HT, Bermann A, Rettig K, Strohmeyer G, Porschen R; Arbeitsgemeinschaft Gastrointestinale Onkologie. 5-Fluorouracil plus leucovorin is an effective adjuvant chemotherapy in curatively resected stage III colon cancer: long-term follow-up results of the adjCCA-01 trial. Ann Oncol 2003;14:395-9.

3. Chau I, Norman AR, Cunningham D, Tait D, Ross PJ, Iveson T, et 
al. A randomised comparison between 6 months of bolus fluorouracil/leucovorin and 12 weeks of protracted venous infusion fluorouracil as adjuvant treatment in colorectal cancer. Ann Oncol 2005;16:549-57.

4. Glimelius B, Dahl O, Cedermark B, Jakobsen A, Bentzen SM, Starkhammar H, et al. Adjuvant chemotherapy in colorectal cancer: a joint analysis of randomised trials by the Nordic Gastrointestinal Tumour Adjuvant Therapy Group. Acta Oncol 2005;44:90412.

5. Biagi JJ, Raphael MJ, Mackillop WJ, Kong W, King WD, Booth CM. Association between time to initiation of adjuvant chemotherapy and survival in colorectal cancer: a systematic review and meta-analysis. JAMA 2011;305:2335-42.

6. Jeong WK, Shin JW, Baek SK. Oncologic outcomes of early adjuvant chemotherapy initiation in patients with stage III colon cancer. Ann Surg Treat Res 2015;89:124-30.

7. Schmoll HJ, Van Cutsem E, Stein A, Valentini V, Glimelius B, Haustermans K, et al. ESMO Consensus Guidelines for management of patients with colon and rectal cancer: a personalized approach to clinical decision making. Ann Oncol 2012;23:2479-516.

8. National Comprehensive Cancer Network (NCCN). NCCN clinical practice guidelines in oncology: colon cancer [Internet]. Plymouth Meeting (PA): NCCN; c2020 [cited 2020 Feb 10]. Available from: https://www.nccn.org/default.aspx.

9. Kang SB, Park JW, Jeong SY, Nam BH, Choi HS, Kim DW, et al. Open versus laparoscopic surgery for mid or low rectal cancer after neoadjuvant chemoradiotherapy (COREAN trial): short-term outcomes of an open-label randomised controlled trial. Lancet Oncol 2010;11:637-45.

10. van der Pas MH, Haglind E, Cuesta MA, Furst A, Lacy AM, Hop WC, et al. Laparoscopic versus open surgery for rectal cancer (COLOR II): short-term outcomes of a randomised, phase 3 trial. Lancet Oncol 2013;14:210-8.

11. Straatman J, Cuesta MA, Tuynman JB, Veenhof AAFA, Bemelman WA, van der Peet DL. C-reactive protein in predicting major post- operative complications are there differences in open and minimally invasive colorectal surgery? Substudy from a randomized clinical trial. Surg Endosc 2018;32:2877-85.

12. Lacy AM, Delgado S, Castells A, Prins HA, Arroyo V, Ibarzabal A, et al. The long-term results of a randomized clinical trial of laparoscopy-assisted versus open surgery for colon cancer. Ann Surg 2008;248:1-7.

13. Mathis KL, Nelson H. Controversies in laparoscopy for colon and rectal cancer. Surg Oncol Clin N Am 2014;23:35-47.

14. Nguyen T, Stern S, Dehal A, Vuong B, Bilchik AJ. Nodal retrieval and short-term outcomes of robotic and laparoscopic colectomies for colon cancer. J Clin Oncol 2019;37:713.

15. Park JS, Kang H, Park SY, Kim HJ, Woo IT, Park IK, et al. Longterm oncologic after robotic versus laparoscopic right colectomy: a prospective randomized study. Surg Endosc 2019;33:2975-81.

16. Fidler IJ, Ellis LM. The implications of angiogenesis for the biology and therapy of cancer metastasis. Cell 1994;79:185-8.

17. Folkman J. What is the evidence that tumors are angiogenesis dependent? J Natl Cancer Inst 1990;82:4-6.

18. Jung YB, Kang J, Park EJ, Baik SH, Lee KY. Time to initiation of adjuvant chemotherapy in colon cancer: comparison of open, laparoscopic, and robotic surgery. J Laparoendosc Adv Surg Tech A 2016;26:799-805.

19. Kang J, Hur H, Min BS, Lee KY, Kim NK. Robotic coloanal anastomosis with or without intersphincteric resection for low rectal cancer: starting with the perianal approach followed by robotic procedure. Ann Surg Oncol 2012;19:154-5.

20. Widmar M, Keskin M, Strombom P, Beltran P, Chow OS, Smith JJ, et al. Lymph node yield in right colectomy for cancer: a comparison of open, laparoscopic and robotic approaches. Colorectal Dis 2017;19:888-94.

21. Pinar I, Fransgaard T, Thygesen LC, Gogenur I. Long-term outcomes of robot-assisted surgery in patients with colorectal cancer. Ann Surg Oncol 2018;25:3906-12. 